\title{
Overexpression of Rad51C splice variants in colorectal tumors
}

\author{
Arjun Kalvala ${ }^{1}$, Li Gao ${ }^{1}$, Brittany Aguila ${ }^{1}$, Tyler Reese ${ }^{1}$, Gregory A. Otterson ${ }^{1,2}$, \\ Miguel A. Villalona-Calero ${ }^{1,2,3}$ and Wenrui Duan ${ }^{1,2}$ \\ ${ }^{1}$ Comprehensive Cancer Center, The Ohio State University College of Medicine and Public Health, Columbus, Ohio, U.S.A \\ 2 Division of Medical Oncology Department of Internal Medicine, The Ohio State University College of Medicine and Public \\ Health, Columbus, Ohio, U.S.A \\ ${ }^{3}$ Department of Pharmacology at The Ohio State University College of Medicine and Public Health, Columbus, Ohio, U.S.A \\ Correspondence to: Miguel A. Villalona-Calero, email: miguel.villalona@osumc.edu \\ Wenrui Duan, email: wenrui.duan@osumc.edu \\ Keywords: Rad51C isoform overexpression, Promoter methylation, Colorectal tumors \\ Received: July 29, $2014 \quad$ Accepted: December 24, $2014 \quad$ Published: December 30, 2014
}

This is an open-access article distributed under the terms of the Creative Commons Attribution License, which permits unrestricted use, distribution, and reproduction in any medium, provided the original author and source are credited.

\section{ABSTRACT}

Functional alterations in Rad51C are the cause of the Fanconi anemia complementation group O (FANCO) gene disorder. We have identified novel splice variants of Rad51C mRNA in colorectal tumors and cells. The alternatively spliced transcript variants are formed either without exon-7 (variant 1), without exon 6 and 7 (variant 2) or without exon 7 and 8 (variant 3 ).

Real time PCR analysis of nine pair-matched colorectal tumors and non-tumors showed that variant 1 was overexpressed in tumors compared to matched nontumors. Among 38 colorectal tumor RNA samples analyzed, 18 contained variant 1, 12 contained variant 2, 14 contained variant 3, and eight expressed full length Rad51C exclusively. Bisulfite DNA sequencing showed promoter methylation of Rad51C in tumor cells. 5-azacytidine treatment of LS-174T cells caused a 14 fold increase in variant 1, a 4.8 fold increase for variant 3 and 3.4 fold for variant 2 compared to 2.5 fold increase in WT.

Expression of Rad51C variants is associated with FANCD2 foci positive colorectal tumors and is associated with microsatellite stability in those tumors. Further investigation is needed to elucidate differential function of the Rad51C variants to evaluate potential effects in drug resistance and DNA repair.

\section{INTRODUCTION}

The Fanconi Anemia (FA) pathway is an example of homologous recombination (HR), repairing DNA damage and maintaining genomic stability. Inherited genetic alterations of FA complementation groups result in FA, characterized by chromosomal instability, congenital musculoskeletal abnormalities, bone marrow failure and susceptibility to cancer [1]. Genetic studies have demonstrated that monoubiquitinated FANCD2 and I by an FA core complex (FANCA, B, C, E, F, G M and L) is impaired during FA $[2,3]$. Once monoubiquitinated, FANCD2 and I co-localize with DNA damage response proteins such as Rad51C (FANCO) to mediate HR repair $[4,5]$. Defects in Rad51C have been documented as the cause of FA complementation group O (FANCO) disorder with a similar phenotype as that seen in FA core complex disorders, including defective DNA damage repair and hypersensitivity to DNA damaging agents [6-8].

In yeast, two hybrid screening and coimmunoprecipitation studies have shown a heterologous interaction between the RAD51 paralogs forming two stable protein complexes, a dimer consisting of Rad51CXRCC3 complex and a larger (BCDX2) complex consisting of XRCC2, RAD51B, C and D [9,10]. Rad51C is the only paralog existing in both complexes $[11,12]$. In vitro, Rad51C is shown to have single stranded DNAdependent ATPase activity through a pairwise interaction with RAD51B [13, 14], and also participates in resolution of holiday junction intermediates by interacting with XRCC2 and Rad51B during late stages of HR [15-17]. 
Alternatively spliced isoforms have been demonstrated to play different or even antagonistic biological roles compared to the full length wild type mRNA in a variety of systems [18-20]. Some of the important diseases caused by cis acting or trans acting protein splicing factors includes cystic fibrosis, dementia, premature aging and cancer [21-24]. Functional characterizations of splice variants of the DNA repair gene Rad52 have previously been shown to increase direct repeat recombination between sister chromatids exchange more often expressed in human and yeast cells [25-27]. A variant of $h \operatorname{Rad} 51, \mathrm{hRad} 51$ delta ex9, resulting from a frame shift mutation causing deletion of exon 9 has been shown to promote higher DNA strand exchange activity when compared to that of hRad51 [28]. Splice variants for Rad51d have been shown to functionally interact with BCDX2 complex in mice and mediate strand-annealing reactions during $\operatorname{HR}[29,30]$.

Although screening for Rad51 founder mutations in patients with colorectal and prostate tumors have shown no mutations [31], little is known of the potential influence of splice variants of this gene in colorectal tumors. Here we report the expression of splice variants of Rad51C in colorectal tumors and cells and differences in the expression of these variants between malignant and normal phenotypes.

\section{RESULTS}

\section{Rad51C splice variants in colorectal tumors}

To investigate the expression of Rad51C in tumors, we isolated total RNA from colorectal tumors. RT-PCR amplification of cDNA between exons 5 and exon 9 of Rad51C using the primers ERF and ERR (Supplementary Table S1) produced three products with sizes of $380 \mathrm{bp}$, $320 \mathrm{bp}$ and $260 \mathrm{bp}$ (Fig. 1A). The purified gel products were subjected to TOPO TA cloning and subjected to sequencing using universal primers. From the sequencing analysis we identified three alternatively spliced variants of the Rad51C gene. The alternatively spliced transcript variant 1 is joined from the 3 '-end of exon- 6 to the 5 '-end of exon-8 (Fig. 1B), variant 2 is joined at the 3'- end of exon- 5 by the 5 '-end of exon- 8 (Fig. 1C), and variant 3 is joined at the 3'-end of exon- 6 with the 5'-end of exon-9 (Fig. 1D). A depiction of Rad51C short variants generated by alternative splicing is shown in Fig. 2A.

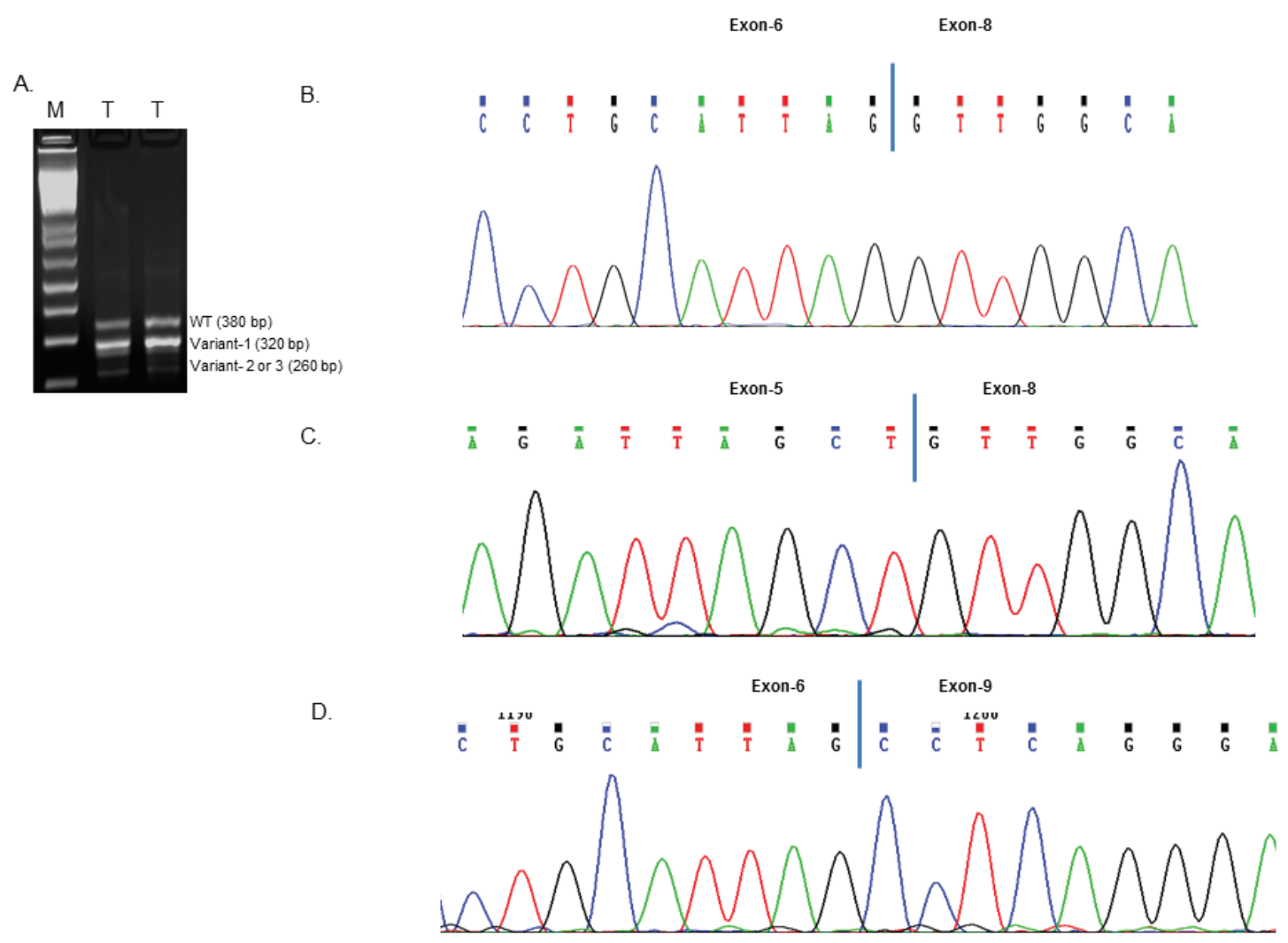

Figure 1: RT-PCR amplification and sequence analysis of Rad51C variants. A) The Total RNA isolated from tumors (T) were RT-PCR amplified using the primers ERF and ERR as mentioned in Supplementary Table S1. The 1.5\% agarose gel electrophoresis image of the amplified cDNA at 380, 320 and $260 \mathrm{bp}$ fragment is shown. The amplified products were subjected to sequencing analysis that shows Rad51C. B) Variant 1 without exon-7; C) Variant 2 without exon-6 and 7 and D) Variant 3 without exon-7 and 8. 
Table 1: Expression of Rad51C variants in tumors

\begin{tabular}{|c|c|c|c|}
\hline S.No & Variant-1 & Variant-2 & Variant- 3 \\
\hline Tumors & $18 / 38(47 \%)$ & $12 / 38(32 \%)$ & $14 / 38(37 \%)$ \\
\hline $\begin{array}{c}\text { Variants expressed in FANCD2 foci negative tumors / } \\
\text { Total negative tumors }\end{array}$ & $2 / 12(17 \%)$ & $2 / 12(17 \%)$ & $1 / 12(8 \%)$ \\
\hline $\begin{array}{c}\text { Variants expressed in FANCD2 foci positive tumors } \\
\text { / Total tumors }\end{array}$ & $16 / 26(62 \%)$ & $10 / 26(39 \%)$ & $13 / 26(50 \%)$ \\
\hline Fishers exact P value & 0.01 & 0.26 & 0.027 \\
\hline
\end{tabular}

\section{Frequency of Rad51C variants in human colorectal tumors}

To evaluate the expression of the alternatively spliced variants in colorectal tumors, we designed variant specific primers based upon the predicted sequences of each cloned variant. The forward and reverse primer sequence for variant 1,2 and 3 with their respective amplicon sizes is shown in Supplementary Table S1. Rad51C variant-specific RT-PCR amplification is shown in Figure 2 (Fig. 2B for variant 1, Fig. 2C for variant 2, and Fig. 2D for variant 3). 18S ribosomal RNA was used as loading control.

Of the 38 colorectal tumors analyzed, 18 (47\%) tumors expressed variant $1,12(32 \%)$ tumors had variant 2 and $14(37 \%)$ tumors expressed variant 3 . The frequency for each variant in tumors is indicated in Table 1.

\section{Rad51C variants are overexpressed in Tumors}

To quantitatively analyze the differential expression of each of Rad51C variant mRNA in colorectal tumors, we compared mRNA expression levels between tumors and corresponding non-tumors using real time PCR.

A.

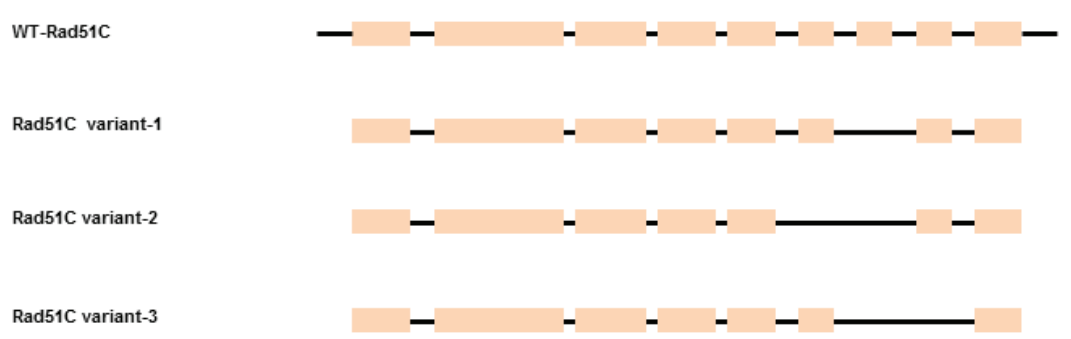

B.

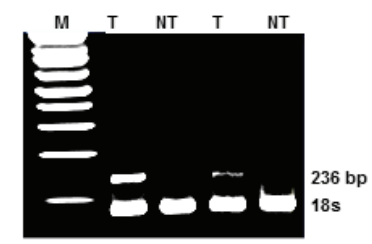

C.

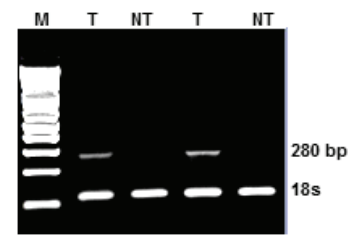

D.

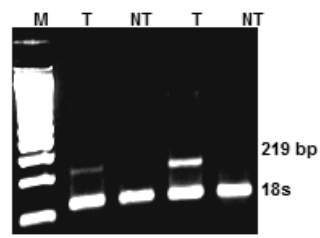

Figure 2: Identification of Rad51C splice variants in colorectal tumors. A) Schematic representation of Rad51C variants. RNA was isolated from a total of 38 colorectal tumors (T) and corresponding non-tumor (NT) and reverse transcribed to cDNA and PCR amplified using variant specific primers (Supplementary Table S1). The electrophoresis gel image of RT-PCR amplified products showed $236 \mathrm{bp}$ fragment for variant 1 (2B); $280 \mathrm{bp}$ fragment for variant 2 (2C) and $219 \mathrm{bp}$ fragment for variant 3 (2D). 18s is loaded as internal control for each variant which is about $120 \mathrm{bp}$ fragment. 
Table 2: Analysis of Rad51C variant expression in FANCD2 Foci tumors with Microsatellite Stability and Instability

\begin{tabular}{|c|c|c|c|c|}
\hline S.No & FancD2 Foci-Positive & FancD2 Foci-Negative & Total & P value \\
\hline FANCD2 Foci & 26 & 12 & 38 & 34 \\
\hline $\begin{array}{c}\text { Microsatellite } \\
\text { Stable (MSS) }\end{array}$ & 25 & 9 & 16 & 0.08 \\
\hline Variant-1 & 15 & 1 & 11 & 0.01 \\
\hline Variant-2 & 9 & 2 & 13 & 0.68 \\
\hline Variant-3 & 12 & 1 & 04 & 0.08 \\
\hline $\begin{array}{c}\text { Microsatellite } \\
\text { Instable (MSI) }\end{array}$ & 1 & 3 & 02 & 0.99 \\
\hline Variant-1 & 1 & 1 & 01 & 0.25 \\
\hline Variant-2 & 1 & 0 & 01 & 0.25 \\
\hline Variant-3 & 1 & 0 & & 0.02 \\
\hline
\end{tabular}

MSS Indicates microsatellite stable; MSI, microsatellite instability

The real time PCR was performed using the primers as mentioned in Supplementary Table S1. These primer pairs amplify amplicons between 100bp and 200bp designed for real time PCR. The $18 \mathrm{~S}$ ribosomal rRNA was used as endogenous control. Relative quantitative analysis of the expression of short variants showed Rad51C variant 1 is over expressed in tumors as compared to non-tumor tissue. On average, variant 1 RNA was 4.95 fold higher in tumors. Variants 2 and 3 were expressed at 2.43 fold and 1.47 fold lower in tumors comparing to non-tumor tissues (Fig. 3). In tumors, the relative expression for each variant compared with wild type Rad51C was 8.05 fold higher for variant $1,1.81$ fold higher for variant 3 and 1.72 fold lower for variant 2 (Supplementary Figure S1).

\section{Rad51C variants and FANCD2 foci}

We next evaluated if the expression of the Rad51C variants correlates with FANCD2 foci formation. We analyzed FANCD2 foci status and Rad51C variants expression in colorectal tumors. Immunofluorescence based FATSI triple staining [32] was used to evaluate FANCD2 foci status. Among 38 tumors, $12(32 \%)$ of samples were noted to lack FANCD2 foci and 26 (68\%) tumors were FANCD2 foci positive.

Of the 12 FANCD2 foci negative tumors, Rad51C variant 1 was present in two (17\%) tumors; two tumors $(17 \%)$ had variant 2 , and one tumor $(8 \%)$ contained variant 3 (Table 2). Among the 26 foci positive tumors,

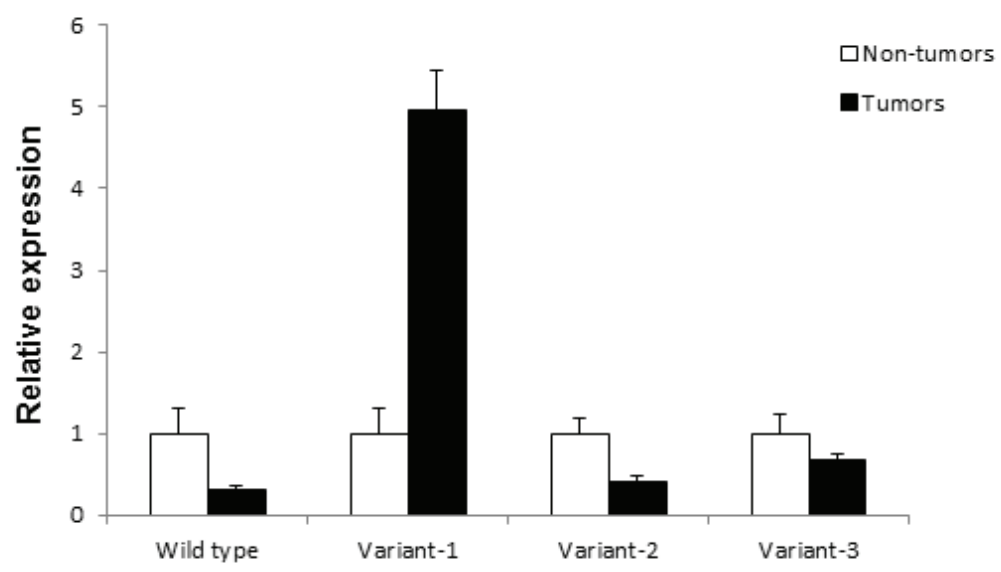

Figure 3: Real time PCR analysis of Rad51C variant expression in colorectal tumors and non-tumors. The total RNA was isolated from 9 colorectal tumors and non-tumors and reverse transcribed to cDNA. The cDNA was then used as template for Rad51C variant expression analysis using the real time specific primers and SYBR green dye (Supplementary Table S1). On average variant 1 was expressed 4.95 fold higher as compared to matched non-tumors. Wild type, variants 2 and 3 were expressed at lower levels. The expression levels are given as relative RNA levels of each of the three variant in folds normalized by the expression level of the non-tumors. 
Rad51C variant 1 was present in $16(62 \%)$ tumors; 10 tumors $(38 \%)$ had variant 2 , and 13 tumors $(50 \%)$ had variant 3 (Table 2).

\section{Rad51C variants expression and microsatellite instability}

Microsatellite instability (MSI) is a condition of genetic hypermutability that results from impaired DNA Mismatch Repair (MMR). MSI is considered an important molecular signature in colorectal cancers, as those patients with MSI high (MSI-H) tumors had a more positive prognosis compared to MSI low (MSI-L) or Microsatellite stable (MSS) tumors [33]. Microsatellite status was obtained from the surgical pathology report based on immunohistochemistry (IHC) analysis evaluating expression of MSH2, MSH6, MLH1 and PMS2 proteins [34] in the 38 tumors examined for $\operatorname{Rad} 51 \mathrm{C}$ variants.
Among the 38 tumors, 34 were MSS tumors and four had MSI. Among the 34 MSS tumors, 16 tumors expressed variant 1,11 variant 2,13 variant 3 , and seven had no expression of the variants. Of the four MSI tumors, two tumors expressed variants and the other two lacked expression of variants. Variant 1 was expressed in two tumors, while variant 2 and variant 3 were expressed in one tumor, which expressed all three variants. The two tumors with MSI without expression of Rad51C variants were low grade, moderately differentiated adenocarcinoma, and had absence of MLH1 and PMS2 protein expression.

\section{Rad51C Promoter methylation in colorectal tumors and cancer cells}

We analyzed the promoter methylation pattern of the Rad51C tumor suppressor gene in the colorectal tumor

A.
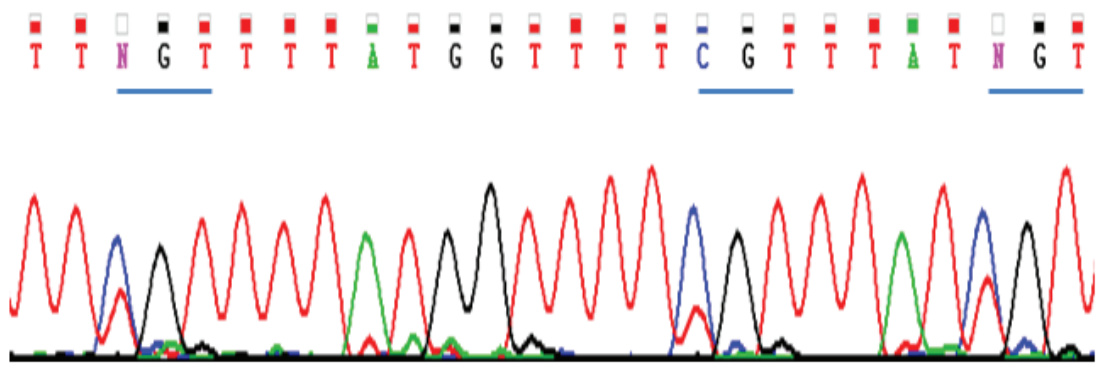

B.

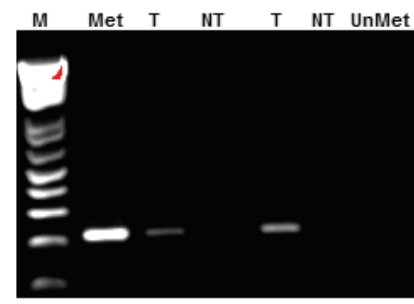

C.

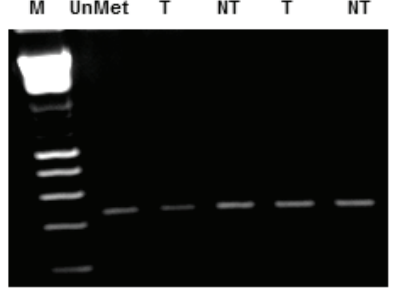

D.

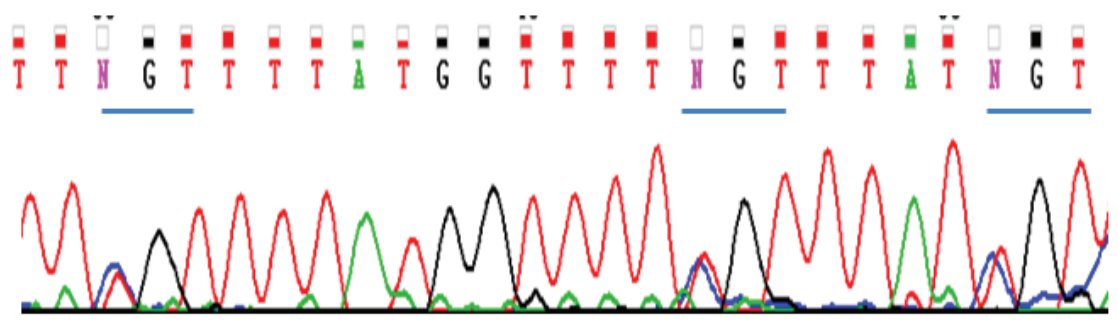

Figure 4: Rad51C Promoter methylation analysis. The DNA was isolated from colorectal tumors and LS-174T cells pre and post 5 -azacytidine treatment at a dose of $5 \mu \mathrm{M}$ for 72 hours. The DNA samples were bisulfite converted and PCR amplified using the primers that amplify the Rad51C promoter region (Supplementary Table S1). A total of $30 \mathrm{CpG}$ sites were located in the product. The PCR amplification produced $408 \mathrm{bp}$ product which is subjected to sequencing. A) The chromatogram for $408 \mathrm{bp}$ product showed methylation at three sites in Rad51C promoter region in colorectal tumors and LS-174T cells. B) The electrophoresis gel image of the methylation specific PCR (MS-PCR) amplification from tumors (T) and Non-tumors (NT) is shown. The Methylated DNA (Met) and Un-methylated DNA (UnMet) is used as controls. The MS-PCR showed methylation in tumors as compared to non-tumors. C) The electrophoresis gel image of the Unmethylated DNA. The PCR amplification of bisulfite converted DNA from tumors (T) and Non-tumors (NT) is shown. The Un-methylated DNA (UnMet) is used as control. D) The colorectal tumor cell LS-174T was treated with 5-azacytidine. Bisulfite sequencing showed demethylation at the three sites of Rad51C promoter region. 
cells. Bisulfite sequencing was used for the analysis. The promoter region of $\operatorname{Rad} 51 \mathrm{C}$ is located on chromosome 17 (between nucleotide positions 56,769,721 and 56,770,129, sequence accession number NC_000017.11). DNA isolated from colorectal tumors and cells was bisulfite treated as described in Materials and Methods. The bisulfite treated DNA was PCR amplified to produce an amplicon fragment of $408 \mathrm{bp}$ using the primers BiProF; BiProF, (Supplementary Table S1). The amplicon contains $30 \mathrm{CpG}$ sites. The PCR amplified bisulfite treated DNA was sequenced (BiProSeqF, BiProSeqR; Supplementary Table S1). The sequence analysis of the bisulfite treated DNA from six colorectal tumors showed three sites that are methylated in the identical position in the promoter region of Rad51C (Fig. 4A). We then analyzed LS-174T colorectal tumor cells for Rad51C promoter methylation and found the same sites methylated as seen in the colorectal tumors. To evaluate the degree of methylation in the promoter region of $\operatorname{Rad} 51 \mathrm{C}$, we conducted methylation specific PCR (MS-PCR) analysis on 19 pair-matched tumor and non-tumor samples. Four of the 19 pairs contain detectable methylation in tumor samples only (Fig. 4B-C), 12 paired samples had no detectable methylation and three paired samples contain detectable methylation in both tumor and non-tumor by MS-PCR. The MS PCR primers for methylated and un-methylated PCRs are shown in the Supplementary Table S1.

\section{Effect of 5-azacytidine on the expression of Rad51C variants}

In view of demonstration of several hypermethylated $\mathrm{CpG}$ sites within the promoter of Rad51C, we wonder if the expression of the observed Rad51C variants could be altered by treatment with DNA hypomethylating agents. To test this, we treated LS-174T cells with 5-azacytidine at $5 \mu \mathrm{M}$ for 72 hours. DNA was isolated and bisulfite treated. A 408bp PCR product was amplified using the primers BiProF and BiProR, (Supplementary Table S1). The PCR amplified products were gel extracted and subjected to sequencing using the primers, BiProSeqF and BiProSeqR (Supplementary Table S1). Sequencing analysis confirmed demethylation at three methylated $\mathrm{CpG}$ sites in the promoter region of Rad51C (Fig. 4D).

To quantitatively analyze the effect of promoter methylation on RNA expression of Rad51C variants, RNA from azacytidine treated cells was reverse transcribed to cDNA and analyzed with SYBR green real time PCR. The real time PCR primers and respective amplicon sizes for variant 1, 2 and 3 are described in Supplementary Table S1. 18S ribosomal rRNA was used as endogenous control in separate reactions. The real time PCR analysis of LS$174 \mathrm{~T}$ colorectal cells treated with 5-azacytidine, showed a 14.3 fold and 4.8 fold increase in the expression of variant 1 and 3, respectively in comparison to untreated controls. The short variant 2 showed a 3.4 fold increase in comparison to untreated controls. Wild type Rad51C had only a 2.5 fold increase post 5 -azacytidine treatment compared to untreated controls (Fig. 5).

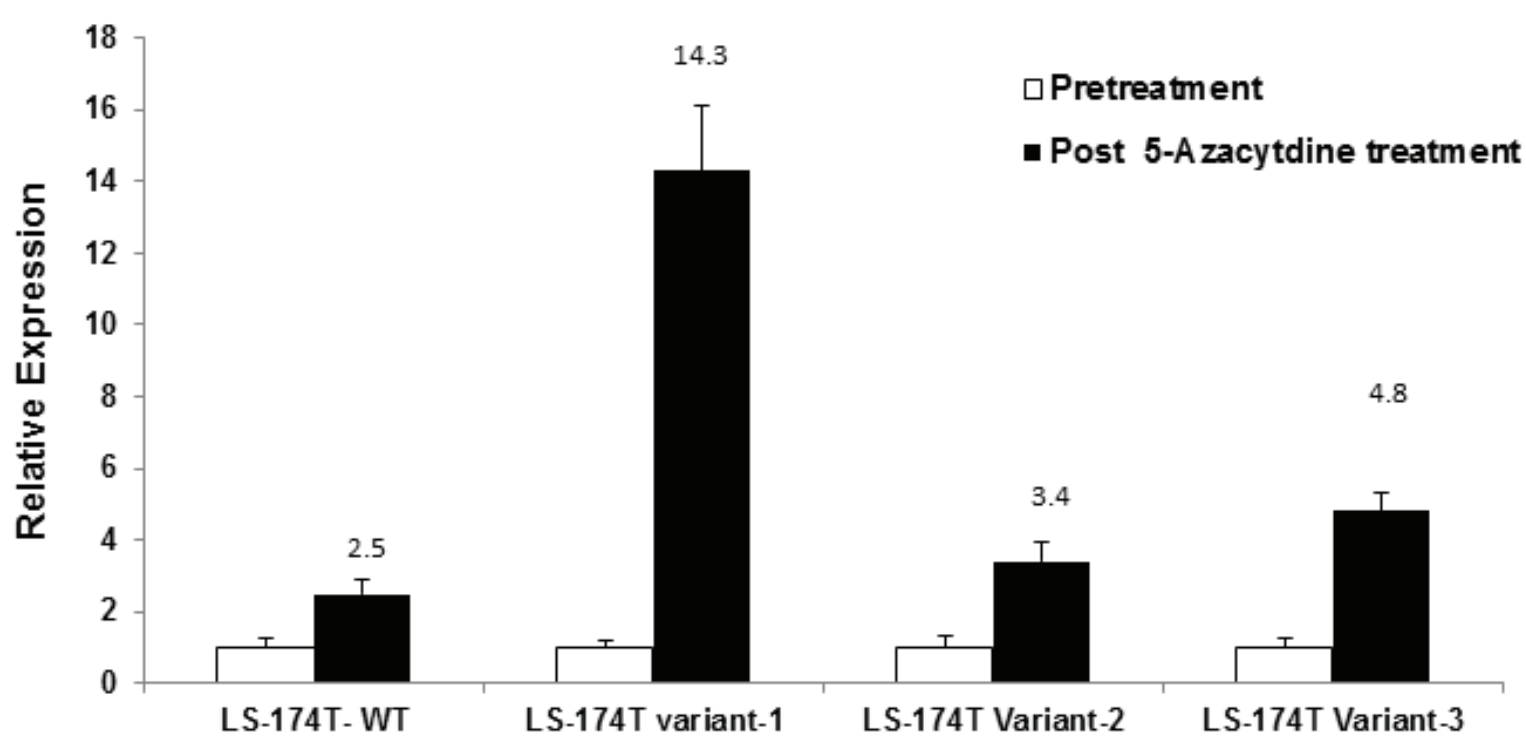

Figure 5: Real time PCR analysis of Rad51C variant expression in LS-174T colorectal tumor cells post 5-azacytidine treatment. The LS-174T cells were treated with 5-azacytidine at dose of $5 \mu \mathrm{M}$ for 72 hours. The total RNA was isolated from pre and post 5-azacytidine treated LS-174T colorectal tumor cells and reverse transcribed to cDNA. The cDNA was then used as template for Rad51C variant expression analysis using real time specific primers and SYBR green dye (Supplementary Table S1). The analysis showed 14.3 fold increase in relative expression of RNA for variant 1, 3.4 folds for variant 2 and 4.8 folds for variant 3, and 2.5 folds increase for wild type. 


\section{Detection of Rad51C protein variants in colorectal tumor cells}

We established the predicted protein sequence of the Rad51C variants by in silico translation using EMBOSS [35]. Variant 1 RNA sequence predicted 46 amino acids (aa) following the alternatively spliced exon-6 of Rad51C, resulting in a new chimeric protein with a predicted molecular weight of $41.6 \mathrm{KDa}$. The RNA sequence analysis for Rad51C variant 2, post exon -5 , showed 24 additional aa and terminates the protein producing a 33.6 KDa protein. Rad51C variant 3 generates a premature stop codon terminating the protein at exon-9 with 4 aa post exon-6 (Supplementary Table S2).

Protein was isolated from colorectal tumors, matched non-tumors and LS-174T cells (Fig 6). The protein was size fractionated on $4-12 \%$ SDS page gel and blotted on nitrocellulose membrane. Rad51C wild type and variant proteins were detected using a mouse monoclonal Rad51C antibody that was predicted to recognize WT and all of the putative variants. Western immunoblot analysis showed that LS-174T cells contained a $47 \mathrm{KDa}$ protein (wild type) and a $41 \mathrm{KDa}$ protein as predicted for $\operatorname{Rad} 51 \mathrm{C}$ variant 1 , and a $33 \mathrm{KDa}$ protein as predicted for variants 2 or 3 . The analysis of proteins from colorectal tumors showed similar variant expression pattern as in LS-174T tumor cells. The analysis of non-tumor protein showed expression of wild type and variant 2 or 3 . Variant 1 was not detected in non-tumor samples.

\section{DISCUSSION}

Sequencing analyses have identified numerous recurrently mutated genes and chromosomal translocations in colorectal cancers [36, 37]. However, information regarding the expression of alternatively spliced gene variants in this malignancy is limited. Recent studies on the Rad51C gene have shown 14 germline sequence alterations among 1100 breast and ovarian tumor samples from patients [6]. Included in these germline alterations is an alternatively spliced isoform of Rad51C without exon-6. This isoform was shown to be involved in tumor cell proliferation [6]. Herein we report the identification of three Rad51C spliced transcript variants, in human colorectal tumors. Variant 1 was overexpressed in tumors.

All three RAD51C variants contained an intact $\mathrm{N}$-terminus domain (exons 1-5). Several studies have shown DNA dependent ATPase activity in the region between exon 2 to exon 5 at aa 125 to 132 of $\operatorname{Rad} 51 \mathrm{C}$ $[10,17]$. Rad51C N-terminus domain is known to form complexes with Rad51B, D and XRCC2 [13, 14], thus variant 1 maintains protein to protein interactive functions. We would hypothesize then that overexpression of variant 1 should stabilize the complex and facilitate DNA repair and replication. To evaluate the biological function of the variant 1 , we performed In vitro transient overexpression of Rad51C variant 1 in HCT116 colorectal tumor cells (Supplementary Figures S2). A 1.8 fold increase in the cell proliferation was recorded in the variant 1 expressing cells as comparing to empty vector transfected controls according to BrdU FACS analysis (Supplementary Figures S3). In addition we evaluated the expression of Rad51C variant 1 in cell proliferation with immunofluorescence staining after labeling with BrdU. We found the cells expressing Rad51C variant 1 had more BrdU positive cells as comparing to cells transfected with empty vector and non-transfected cells (Supplementary Figures S4). These In vitro data suggest the Rad51C variant 1 may promote cell proliferation in colorectal tumors.

Promoter methylation of Rad51C has been shown in breast and ovarian cancer patients [38]. Here we show promoter methylation of Rad51C in colorectal tumor and LS-174T DNA samples. DNA methylation is

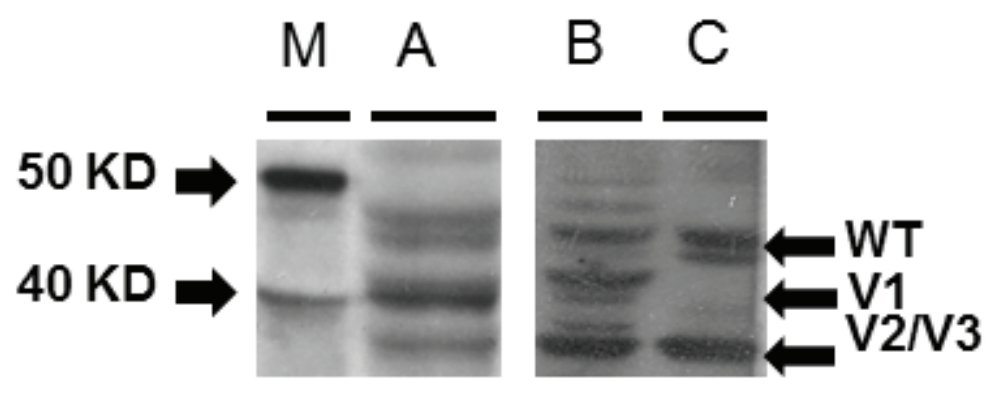

Figure 6: Western immunoblot analysis for Rad51C variant protein expression from colorectal tumors, matched nontumors and LS-174T cells. Protein was isolated from colorectal tumors, matched non-tumors and LS-174T cells. The protein was analyzed on $4-12 \%$ SDS page gel and blotted on nitrocellulose membrane. Rad51C wild type and variant proteins were detected using a mouse monoclonal Rad51C antibody. Western analysis showed the proteins from LS-174T cells contained a 47 KDa protein for wild type and a $41 \mathrm{KDa}$ for predicted Rad51C variant 1 and $33 \mathrm{KDa}$ for predicted variant 2 or 3 (A). The analysis of proteins from colorectal tumor showed similar variant expression pattern as in LS-174T tumor cells (B). The analysis of non-tumor protein showed expression of wild type and variant 2 or 3 . The variant 1 was absent in non-tumor protein $(\mathrm{C})$. 
known to exert multiple functions including regulation of gene expression, determining alternate poly A choice and tissue specific selection of alternate promoters [39]. It has been shown that Methyl CpG (MECP2) binding proteins are enriched in alternatively spliced exons and chemical or genetic disruption ablates the aberrant exon skipping events [40]. Our results show that the Rad51C variants expression was up regulated after treatment with 5-azacytidine, a classic demethylation agent. This indicates that Rad51C promoter methylation can regulate the expression of variants in colorectal tumors. Further investigation is needed to elucidate differential function of the Rad51C variant 1, given its association with the malignant phenotype, and its higher degree of response to demethylation agents. Experiments to evaluate its potential effect in drug resistance and DNA repair are under way in our laboratory.

\section{MATERIALS AND METHODS}

\section{Patient tumor tissue samples collection}

The human tumor tissue samples were obtained from the tissue procurement shared resources of The Ohio State University Comprehensive Cancer Center, after institutional review board approval. Tumor characteristics such as histology, tumor site and size as well as microsatellite stability parameters were obtained from the pathology report. The processed samples were excised into formalin fixed and paraffin embedded (FFPE) and frozen samples. The frozen samples were stored in a $-80^{\circ} \mathrm{C}$ freezer for RNA and DNA extraction.

\section{RNA and DNA analysis}

The total RNA and DNA were isolated by homogenization and sequential precipitation following the protocol from TRIzol reagent (Life Technologies, CA). The RNA and DNA obtained from the colorectal tumor tissue samples was quantified at absorbance $260 \mathrm{~nm}$ and $280 \mathrm{~nm}$ using Nanodrop 2000C (Thermoscientific, DE).

\section{RT-PCR}

The RT-PCR primers were designed using the automated Primer3 [41]. The RT-PCR was performed in $25 \mu \mathrm{l}$ reaction containing final concentration $(1 \mathrm{x})$ of $5 \mu \mathrm{l}$ of 5x Qiagen One-step RT-PCR buffer, $400 \mu \mathrm{M}$ of each dNTPs, $0.6 \mu \mathrm{M}$ each of forward and reverse primers, $1 \mu \mathrm{l}$ of Qiagen One step RT-PCR enzyme mix and template RNA up to 400ng and volume made up to $25 \mu \mathrm{l}$ using PCR grade water. The cDNA of about 200ng was PCR amplified for $30 \mathrm{~min}$ at $54^{\circ} \mathrm{C}$, initial heat activation for
$15 \mathrm{~min}$ at $95^{\circ} \mathrm{C}, 33$ cycles of initial denaturation for 30 sec at $94^{\circ} \mathrm{C}$, annealing for $30 \mathrm{sec}$ at $61^{\circ} \mathrm{C}$, extension for 30 seconds at $72^{\circ} \mathrm{C}$, final extension for $5 \mathrm{~min}$ at $72^{\circ} \mathrm{C}$. The forward and reverse primers used for RT-PCR and their amplicon sizes are mentioned in (Supplementary Table S1). To identify each of the variant, variant specific primers that span exon junctions were designed. All primers are listed in the Supplementary Table S1.

\section{FANCD2 foci identification}

The FA triple staining immunofluorescence method previously developed in our laboratory [32] was used to assess the FANCD2 foci in colorectal tumor tissues.

\section{5-azacytidine (5-aza) treatment of cells}

Human colon cancer cell lines LS-174T purchased from $\mathrm{ATCC}^{\circledR}$ were grown in complete EMEM medium with $10 \%$ fetal bovine serum and $1 \%$ penicillin/ streptomycin at $37^{\circ} \mathrm{C}\left(5 \%, \mathrm{CO}_{2}\right)$. For the treatment of cells, 5 -azacytidine was filter-sterilized and added directly to the fresh cell culture media. Fresh 5-azacytidine was added every 24 hours at dose of $5 \mu \mathrm{M}$ for 72 hours. The post treatment cells were lysed, and the pellets were collected and stored at $-80^{\circ} \mathrm{C}$.

\section{Bisulfite sequencing and promoter methylation}

Bisulfite conversion of genomic DNA from colorectal tumors and cells was performed with EpiTect 96 Bisulfite kit (Qiagen, Hilden, Germany). The promoter region of Rad51C was retrieved from the Ensemble browser (http://www.ensembl.org/Homo_sapiens/). The prediction of $\mathrm{CpG}$ islands and PCR primer sequences were designed using Meth primer program [42]. PCR amplification of the bisulfite DNA was performed in $25 \mu 1$ reaction using $1 \mathrm{x}$ methylation specific PCR buffer, $10 \mathrm{mM}$ of dNTP mix, $0.4 \mu \mathrm{M}$ of each forward and reverse primers, $1 \mu \mathrm{l}$ of $(\sim 150 \mathrm{ng})$ of bisulfite treated DNA sample and 0.4 $\mu l$ of 1.0 unit Platinum ${ }^{\circledR}$ Taq DNA polymerase following the protocol from (Invitrogen). PCR was carried out with initial heat denaturation step of $95^{\circ} \mathrm{C}$ for $10 \mathrm{~min}, 38$ cycles of $95^{\circ} \mathrm{C}$ for $30 \mathrm{~s}$, annealing at $61^{\circ} \mathrm{C}$ for $30 \mathrm{~s}$, extension at $72^{\circ} \mathrm{C}$ for $30 \mathrm{~s}$ and final extension step at $72^{\circ} \mathrm{C}$ for $5 \mathrm{~min}$. The amplified products were gel extracted and purified using the QIAquick Gel Extraction Kit (Qiagen, CA) and subjected to sequencing using primers mentioned in (Supplementary Table S1). The Methylation specific PCR (MS-PCR) was carried out with EpiTect MSP kit (Qiagen, $\mathrm{CA}$ ) using the $2 \mathrm{X}$ master mix following the manufacturer recommendations. The PCR was carried out with initial heat denaturation step of $95^{\circ} \mathrm{C}$ for $10 \mathrm{~min}, 38$ cycles of $95^{\circ} \mathrm{C}$ for $15 \mathrm{~s}$, annealing at $51^{\circ} \mathrm{C}$ for $30 \mathrm{~s}$, extension at $72^{\circ} \mathrm{C}$ 
for $30 \mathrm{~s}$ and final extension step at $72^{\circ} \mathrm{C}$ for $5 \mathrm{~min}$.

\section{Real time PCR}

The RNA expression levels of the Rad51C variants were analyzed by SYBR green real time PCR. The RNA isolated from colorectal tumor cells were treated with 5-azacytidine and reverse transcribed to cDNA using Superscript ${ }^{\text {TM }}$ II Reverse Transcriptase from Invitrogen (CA, USA). The primers for real time PCR amplification were designed using Primer3 software [41]. The SYBR green real time Quantitect PCR kit was purchased from Qiagen Sciences (Maryland, USA). The primers used for real time PCR amplification are mentioned in Supplementary Table S1. The cDNA was used as template and the final reaction consisted of $1 x$ SYBR green master mix, $10 \mathrm{pmol} / \mu \mathrm{l}$ of forward and reverse primers. Also human 18S rRNA is used as internal control in separate reactions.

\section{Immunoblot}

Equal amount of proteins were size-fractionated on $4-12 \%$ NuPAGE. Proteins were then transferred onto nitrocellulose membrane. The membrane was blocked with blocking buffer (5\% nonfat milk). The blocked membrane was then incubated with target mouse monoclonal Rad51C antibody (Sigma Aldrich ${ }^{\circledR}, \mathrm{MO}$ ) at $4^{\circ} \mathrm{C}$ overnight. After washing the membrane with TBS-T (20mM Tris, $0.9 \% \mathrm{Nacl}$ ) for three times 30 minutes each, the membrane was then incubated with anti- mouse secondary antibody $\left(\right.$ Sigma Aldrich $\left.{ }^{\circledR}, \mathrm{MO}\right)$ for $1 \mathrm{~h}$ at room temperature. After washing five times, 10 minutes each, a chemiluminescent detection system (ECL western blotting detection reagents, GE Healthcare) was used to detect the secondary antibody. Finally the membranes were exposed to X-ray films.

\section{ACKNOWLEDGEMENTS}

We thank the Pathology Core Lab and Tissue Procurement facilities of the OSUCCC, and The Cooperative Human Tissue Network Midwestern Division at The Ohio State University, for their assistance. We would like to thank Fernando Ochoa Cortes, Department of Anesthesiology for his valuable help in microscopy images and Xin Wu for advice on Flow cytometry. We thank David Carbone and his lab colleagues, especially Joe Amman for his timely advice on experiments. This work was supported by NCI R01CA152101 (to M. V); NCI grant P30 CA16058 (to The Ohio State University, Comprehensive Cancer Center).

\section{Author Contributions}

A.K conceived, designed, performed experiments and wrote manuscript, L.G performed experiments, B.A performed experiments, T.R performed experiments, G.A.O designed experiments, edited manuscript, M.A.V conceived, designed experiments, edited manuscript, W.D conceived, designed and performed experiments and edited manuscript.

\section{REFERENCES}

1. Kee Y and D'Andrea AD. Molecular pathogenesis and clinical management of Fanconi anemia. J Clin Invest. 2012; 122: 3799-3806.

2. Meetei AR, de Winter JP, Medhurst AL, Wallisch M, Waisfisz Q, van de Vrugt HJ, Oostra AB, Yan Z, Ling C, Bishop CE, Hoatlin ME, Joenje H, Wang W. A novel ubiquitin ligase is deficient in Fanconi anemia. Nat Genet. 2003; 35: 165-170.

3. Andreassen PR, D'Andrea AD, Taniguchi T. ATR couples FANCD2 monoubiquitination to the DNA-damage response. Genes Dev. 2004; 18: 1958-1963.

4. Wang X, Andreassen PR, D'Andrea AD. Functional interaction of monoubiquitinated FANCD2 and BRCA2/ FANCD1 in chromatin. Mol Cell Biol. 2004; 24: 58505862.

5. Medhurst AL, Laghmani el H, Steltenpool J, Ferrer M, Fontaine C, de Groot J, Rooimans MA, Scheper RJ, Meetei AR, Wang W, Joenje H, de Winter JP. Evidence for subcomplexes in the Fanconi anemia pathway. Blood. 2006; 108: 2072-2080.

6. Meindl A, Hellebrand H, Wiek C, Erven V, et al. Germline mutations in breast and ovarian cancer pedigrees establish RAD51C as a human cancer susceptibility gene. Nat Genet. 2010; 42: 410-414.

7. Sellick G, Fielding S, Qureshi M, Catovsky D; International Familial CLL Consortium, Houlston R. Germline mutations in RAD51, RAD51AP1, RAD51B, RAD51C,RAD51D, RAD52 and RAD54L do not contribute to familial chronic lymphocytic leukemia. Leuk Lymphoma. 2008; 49: 130133.

8. Vaz F, Hanenberg H, Schuster B, Barker K, Wiek C, et al. Mutation of the RAD51C gene in a Fanconi anemia-like disorder. Nat Genet. 2010; 42: 406-409.

9. Schild D, Lio YC, Collins DW, Tsomondo T, Chen DJ. Evidence for simultaneous protein interactions between human Rad51 paralogs. J Biol Chem. 2000; 275: 1644316449.

10. Lio YC, Mazin AV, Kowalczykowski SC, Chen DJ. Complex formation by the human Rad51B and Rad51C DNA repair proteins and their activities in vitro. J Biol Chem. 2003; 278: 2469-2478.

11. Yokoyama H, Sarai N, Kagawa W, Enomoto R, Shibata 
T, Kurumizaka H, Yokoyama S. Preferential binding to branched DNA strands and strand-annealing activity of the human Rad51B, Rad51C, Rad51D and Xrcc2 protein complex. Nucleic Acids Res. 2004; 32: 2556-2565.

12. Compton SA, Ozgür S, Griffith JD. Ring-shaped Rad51 paralog protein complexes bind Holliday junctions and replication forks as visualized by electron microscopy. J Biol Chem. 2010; 285: 13349-13356.

13. Miller KA, Yoshikawa DM, McConnell IR, Clark R, Schild D, Albala JS. RAD51C interacts with RAD51B and is central to a larger protein complex in vivo exclusive of RAD51. J Biol Chem. 2002; 277: 8406-8411.

14. Wiese C, Collins DW, Albala JS, Thompson LH, Kronenberg A, Schild D. Interactions involving the Rad51 paralogs Rad51C and XRCC3 in human cells. Nucleic Acids Res. 2002; 30: 1001-1008.

15. Somyajit K, Subramanya S, Nagaraju G. RAD51C: a novel cancer susceptibility gene is linked to Fanconi anemia and breast cancer. Carcinogenesis. 2010; 31: 2031-2038.

16. Stackpole MM, Wise SS, Goodale BC, Duzevik EG, Munroe RC, Thompson WD, Thacker J, Thompson LH, Hinz JM, Wise JP Sr. Homologous recombination repair protects against particulate chromate-induced chromosome instability in Chinese hamster cells. Mutat Res. 2007; 625: 138-154.

17. Bennett BT, Knight KL. Cellular localization of human Rad51C and regulation of ubiquitin-mediated proteolysis of Rad51. J Cell Biochem. 2005; 96: 1095-1109.

18. Menon R, Zhang Q, Zhang Y, Fermin D, Bardeesy N, DePinho RA, Lu C, Hanash SM, Omenn GS, States DJ. Identification of novel alternative splice isoforms of circulating proteins in a mouse model of human pancreatic cancer. Cancer Res. 2009; 69: 300-309.

19. Depontieu F, Grigoriu BD, Scherpereel A, Adam E, Delehedde M, Gosset P, Lassalle P. Loss of Endocan tumorigenic properties after alternative splicing of exon 2 . BMC Cancer. 2008; 8: 14

20. Bronicki LM, Jasmin BJ. Trans-acting factors governing acetylcholinesterase mRNA metabolism in neurons. Front Mol Neurosci. 2012; 5: 36.

21. Caux-Moncoutier V, Pagès-Berhouet S, Michaux D, Asselain B, Castéra L, De Pauw A, Buecher B, GauthierVillars M, Stoppa-Lyonnet D, Houdayer C. Impact of BRCA1 and BRCA2 variants on splicing: clues from an allelic imbalance study. Eur J Hum Genet. 2009; 17: 14711480 .

22. Luo YB, Mastaglia FL, Wilton SD. Normal and aberrant splicing of LMNA. J Med Genet. 2014; 51:215-23.

23. Rodriguez-Martin T, Anthony K, Garcia-Blanco MA, Mansfield SG, Anderton BH, Gallo JM. Correction of tau mis-splicing caused by FTDP-17 MAPT mutations by spliceosome-mediated RNA trans-splicing. Hum Mol Genet. 2009; 18: 3266-3273.

24. Garcia-Blanco MA, Baraniak AP, Lasda EL. Alternative splicing in disease and therapy. Nat Biotechnol. 2004; 22: 535-546.

25. Bell DW, Wahrer DC, Kang DH, MacMahon MS, FitzGerald MG, Ishioka C, Isselbacher KJ, Krainer M, Haber DA. Common nonsense mutations in RAD52. Cancer Res. 1999; 59: 3883-3888.

26. Kuschel B, Auranen A, McBride S, Novik KL, Antoniou A, Lipscombe JM, Day NE, Easton DF, Ponder BA, Pharoah PD, Dunning A. Variants in DNA double-strand break repair genes and breast cancer susceptibility. Hum Mol Genet. 2002; 11: 1399-1407.

27. Shi TY, Yang G, Tu XY, Yang JM, Qian J, Wu XH, Zhou XY, Cheng X, Wei Q . RAD52 variants predict platinum resistance and prognosis of cervical cancer. PLoS One. 2012; 7: e50461.

28. Sevcik J, Falk M, Macurek L, Kleiblova P, Lhota F, Hojny J, Stefancikova L, Janatova M, Bartek J, Stribrna J, Hodny Z, Jezkova L, Pohlreich P, Kleibl Z. Expression of human BRCA1Delta17-19 alternative splicing variant with a truncated BRCT domain in MCF-7 cells results in impaired assembly of DNA repair complexes and aberrant DNA damage response. Cell Signal. 2013; 25: 1186-1193.

29. Kawabata M, Akiyama K, Kawabata T. Genomic structure and multiple alternative transcripts of the mouse TRAD/ RAD51L3/RAD51D gene, a member of the recA/RAD51 gene family. Biochim Biophys Acta. 2004; 1679: 107-116.

30. Gruver AM, Yard BD, McInnes C, Rajesh C, Pittman DL. Functional characterization and identification of mouse Rad51d splice variants. BMC Mol Biol. 2009; 10: 27.

31. Pelttari LM, Nurminen R, Gylfe A, Aaltonen LA , Schleutker $J$ and Nevanlinna H. Screening of Finnish RAD51C founder mutations in prostate and colorectal cancer patients. BMC Cancer. 2012; 12:552

32. Duan W, Gao L, Zhao W, Leon M, Sadee W, Webb A, Resnick K, Wu X, Ramaswamy B, Cohn DE, Shapiro C, Andreassen PR, Otterson GA, Villalona-Calero MA. Assessment of FANCD2 nuclear foci formation in paraffinembedded tumors: a potential patient-enrichment strategy for treatment with DNA interstrands crosslinking agents. Transl Res. 2013; 161: 156-164.

33. Popat S, Hubner R, Houlston RS. Systematic review of microsatellite instability and colorectal cancer prognosis. $\mathrm{J}$ Clin Oncol. 2005; 23: 609-18.

34. South CD, Yearsley M, Martin E, Arnold M, Frankel W, Hampel H. Immunohistochemistry staining for the mismatch repair proteins in the clinical care of patients with colorectal cancer. Genet Med. 2009; 11: 812-7.

35. Rice P, Longden I, Bleasby A. EMBOSS: the European Molecular Biology Open Software Suite. Trends Genet. 2000; 16: 276-277.

36. Bass AJ, Lawrence MS, Brace LE, Ramos AH, Drier Y, et al. Genomic sequencing of colorectal adenocarcinomas identifies a recurrent VTI1A-TCF7L2 fusion. Nat Genet. 2011; 43: 964-8. 
37. Seshagiri S, Stawiski EW, Durinck S, Modrusan Z, Storm EE, Conboy CB, Chaudhuri S, Guan Y, Janakiraman V, Jaiswal BS, Guillory J, Ha C, Dijkgraaf GJ, et al. Recurrent R-spondin fusions in colon cancer. Nature. 2012; 488: 6604.

38. Hansmann T, Pliushch G, Leubner M, Kroll P, Endt D, Gehrig A, Preisler-Adams S, Wieacker P, Haaf T. Constitutive promoter methylation of BRCA1 and RAD51C in patients with familial ovarian cancer and early-onset sporadic breast cancer. Hum Mol Genet. 2012; 21: 46694679.

39. Nott A, Le Hir H, Melissa JM. Splicing enhances translation in mammalian cells: an additional function of the exon junction complex 2. Genes Dev. 2004; 18: 210-222.

40. Maunakea AK, Chepelev I, Cui K, Zhao K. Intragenic DNA methylation modulates alternative splicing by recruiting MeCP2 to promote exon recognition. Cell Res. 2013; 23:1256-69

41. Rozen S, Skaletsky H. Primer3 on the WWW for general users and for biologist programmers. Methods Mol Biol. 2000; 132: 365-386.

42. Li LC and Dahiya R. MethPrimer: designing primers for methylation PCRs. Bioinformatics. 2002; 18: 1427-31. 